\title{
FutureJournal
}

\section{Tecnologia e Competências Tecnológicas em Educação a Distância: um Estudo Exploratório}

\author{
Dimária Silva e Meirelles, \\ Universidade Presbiteriana Mackenzie, Brasil \\ dmeirelles@gmail.com \\ Felix Hugo Aguero Diaz Leon, \\ Universidade Presbiteriana Mackenzie, Brasil \\ Felix.leon@mackenzie.br \\ Luciano Augusto Pereira dos Santos, \\ Universidade Presbiteriana Mackenzie, Brasil \\ sanpol@uol.com.br \\ Rachel Neves Dias Francisco \\ Faculdade Sumaré, Brasil \\ rachelndf@gmail.com
}

\section{RESUMO}

Nesta pesquisa o objetivo geral foi identificar os elementos componentes das competências tecnológicas em serviços por meio do estudo do uso da tecnologia e de seus impactos nas práticas organizacionais. A abordagem de pesquisa incluiu uma etapa qualitativa, baseada em entrevistas com desenvolvedores, usuários e gestores de tecnologia. A principal contribuição da pesquisa foi a identificação das tecnologias utilizadas a partir de uma perspectiva que reúne tanto a ótica do usuário quanto a do desenvolvedor, pela qual são analisados os desdobramentos em termos de práticas organizacionais e desempenho no segmento de Educação a Distância (EAD). A análise das entrevistas sugere que ainda há resistência em relação à adoção da tecnologia, e que o desenvolvimento da competência tecnológica ainda se encontra nos estágios iniciais. Nos casos em que a tecnologia é utilizada com intensidade, as mudanças nas práticas e no desempenho ocorrem indistintamente, com benefícios claros em termos de rapidez, eficiência e ganhos de escala.

PALAVRAS-CHAVE: Tecnologia. Serviços. Competência tecnológica. Educação a distância. 


\title{
FutureJournal
}

\section{Technological Competences in Distance Education: an Exploratory Study}

\begin{abstract}
This research has the general objective to identify the components of services technological competences through the study of the use of technology and its impact in organizational practices. The research approach included a qualitative step, based on interviews with developers, users and technology managers. The main contribution here was to identify the using of technology from a perspective that brings together both the user's perspective as the developer, which analyzes the developments in terms of organizational practices and performance in the distance education field. The results suggests that there is still resistance in the adoption of technology and the development of technological expertise is still in the early stages. In cases where the technology is used with intensity, changes in practices and performance occur indiscriminately, with clear benefits in terms of speed, efficiency and scale gains.
\end{abstract}

KEY-WORDS: Technology. Services. Technological competences. Distance education. 


\section{INTRODUÇÃO}

A Associação Brasileira de Ensino a Distância (ABED) define EAD como a modalidade de educação cujas atividades de ensino-aprendizagem se desenvolvem exclusiva ou majoritariamente sem alunos e professores presentes na mesma hora e lugar (ABED, n.d.). Para atingir qualidade em EAD, é importante valorizar a preocupação com as pessoas, utilizando-se o potencial das ferramentas disponíveis (Versuti,2004).

O objetivo geral nesta pesquisa é identificar os elementos componentes das competências tecnológicas em serviços de EAD por meio do estudo do uso e dos impactos da tecnologia nas práticas organizacionais. Para tanto, estabeleceram-se quatro objetivos específicos: 1) caracterizar as tecnologias utilizadas em EAD; 2) identificar as especificidades da articulação agentes/estrutura no uso da tecnologia; 3) identificar os elementos de competência tecnológica que emergem do uso das tecnologias de EAD; 4) comparar as diferenças entre as dimensões das competências tecnológicas identificadas nas empresas analisadas e propor indicadores de competência tecnológica em serviços de EAD.

Ao discutir tecnologia, Orlikowski (1992) assinala que ela é criada e alterada pela ação humana; é utilizada pelo homem para realizar alguma ação; sendo essa ação contínua que a objetiva e institucionaliza. A partir da teoria estruturacionista de Giddens (1984), a autora propõe que a interação do homem com a tecnologia constitui a propriedade estrutural da organização. Mais tarde, Orlikowski (2000) propõe ênfase no processo de constituição da tecnologia por meio da prática. Novos produtos são criados a partir da articulação de competências relacionadas entre a tecnologia e o consumidor (Danneels, 2002), sendo competência um conceito que requer uma visão do desempenho humano na realização do trabalho (Sandberg, 2000). A escolha e o grau de formalização dos processos de aprendizado definem a complexidade da capacidade tecnológica e revelam o grau de maturidade tecnológica da firma (Fransman, 1984; Lall, 1992). Vários autores consideram capacidade tecnológica a principal de uma firma (Nelson \& Winter, 1982; Teece, Rumelt, Dosi \& Winter, 1994), de uma população de empresas (McKelvey, 1982) ou de um país (Lall, 1992). 
O pressuposto fundamental desta pesquisa foi 0 de que 0 desenvolvimento da competência tecnológica em EAD ocorre a partir do uso da tecnologia em coordenação com recursos humanos e causa impactos nas práticas organizacionais.

Trata-se de um estudo exploratório, realizado por meio da pesquisa qualitativa interpretativa básica, que buscou identificar as tecnologias utilizadas em EAD e as especificidades no seu uso. Os dados primários, coletados por meio de entrevistas com desenvolvedores e usuários dessas tecnologias, foram analisados segundo o modelo de Flores (1994).

\section{REVISÃO BIBLIOGRÁFICA}

\subsection{TECNOLOGIA EM EDUCAÇÃO A DISTÂNCIA}

A legislação brasileira, decreto 2.494/1998, define EAD como a forma de ensino que possibilita a autoaprendizagem, com a mediação de recursos didáticos sistematicamente organizados, apresentados em diferentes suportes de informação, utilizados isoladamente ou combinados, e veiculados pelos diversos meios de comunicação.

A EAD não é uma tecnologia nova. Para Peters (1973), seus primeiros traços surgiram em meados do século XIX na Europa e contaram com a ajuda do transporte e da comunicação, que permitiram o ensino por correspondência.

As tecnologias de EAD podem ser utilizadas em cursos presenciais, semipresenciais (blended learning) e a distância (e-learning) (Machado, Longhi \& Behar, 2013).

De acordo com Rumble (2000), a EAD apresenta quatro gerações: a primeira baseada em textos, impressos ou escritos à mão, por meio de correspondência; a segunda em recursos tecnológicos audiovisuais, como rádio e televisão; a terceira geração foi a junção das duas anteriores, tendo como base textos, áudio e vídeo; e, por fim, a quarta teve apoio do avanço tecnológico, a era digital, mediada por computadores; nela a comunicação pode ser feita por acessos virtuais a bancos de informações e dados, videoconferências, bibliotecas eletrônicas, chats e e-mails. 
Esta última geração de EAD inclui o uso de bancos de dados inteligentes, que criam "aprendizagem flexível inteligente" (Taylor, 2002) e incorporam tecnologias da Web 2.0 ou Web semântica (Anderson \& Dron, 2012).

Conforme destacam Machado et al. (2013), junto com a Web 2.0 há o cloud computing, no qual não é mais necessário instalar softwares nos computadores ou em qualquer outro dispositivo, pois o acesso aos programas acontece diretamente na Internet, sendo possível editar, acrescentar, compartilhar e salvar diferentes tipos de arquivos.

Um ponto importante destacado por Anderson e Dron (2012) é que nenhuma geração, ao longo do tempo, eliminou a anterior e, portanto, tanto o aluno, quanto o designer de EAD tiveram suas opções aumentadas.

O início de um projeto de EAD implica a escolha do AVA (Ambiente Virtual de Aprendizagem) ou LMS (Learning Management System) (Fernandes, Fernandes, Silva, Araújo \& Cavalcante, 2010), também conhecido como plataforma de EAD, por empregar uma infraestrutura tecnológica com recursos que atendem a objetivos pedagógicos (Machado et al., 2013).

O AVA é o espaço na Internet que possibilita a criação de um ambiente educacional, quase sempre relacionado à organização de cursos e disciplinas, à administração de conteúdo e ao monitoramento dos alunos, suportando um universo virtual composto pelo aparato tecnológico, pelo gerenciamento das informações, pelos indivíduos e por suas interações (Behar et al., 2013) desenvolvidos com base em pressupostos pedagógicos. Seu objetivo é simplificar a administração dos cursos, auxiliar os alunos no planejamento individual do processo de aprendizagem e possibilitar a troca de informações e conhecimento (Maia, 2012).

Várias são as plataformas AVA utilizadas. De acordo com estudo recente realizado por Clarenc, Castro, Carmen López e Tosco (2013), são mais de 19 plataformas em uso. No Brasil, a plataforma mais utilizada é o Modular Object-Oriented Dynamic Learning Environment (Moodle). Trata-se de um sistema de código aberto, cujas vantagens estão na disponibilização e adaptação segundo as necessidades de cada instituição, sem custo envolvido (Fernandes et al., 2010; Santos, 2012). 
O Moodle foi criado em 1999 pelo webmaster Martin Dougiamas, da Curtin University of Technology, na Austrália, responsável pela administração do AVA usado pela universidade (Fernandes et al., 2010; Santos, 2012). Seu objetivo foi fazer um melhor uso da Internet proporcionando às pessoas uma alternativa gratuita e livre, que pudesse introduzi-las ao universo on-line.

Além do AVA, cabe destacar o uso dos objetos de aprendizagem (OA), definidos como qualquer material digital (vídeo, sons, animações, etc.) que tem objetivo educativo, ou seja, um embasamento pedagógico, dividido em três categorias (Machado et al., 2013):

- $\quad$ simples: pouca interação do usuário com o objeto. Ex.: texto;

- intermediário: interação limitada, uma fonte de informação. Ex.: vídeo;

- complexo: possibilita maior interação e interatividade do usuário com o objeto. Ex.: portais.

A escolha do OA é feita pelo formador e pelo gestor que devem escolher aquele que trará mais significado para a aprendizagem do aluno (Machado et al., 2013).

Uma forma de ter maior interatividade é a aula via satélite, que apresenta a capacidade de atendimento a milhares de alunos simultaneamente, de diferentes regiões, com a possibilidade de atingir municípios que não tinham instituições de ensino tradicionais (Assis, 2012). A autora afirma que esse método facilita a interação síncrona, por meio do envio de perguntas e participação via chat ou voz, garantindo a interatividade entre alunos e professores e trouxe importante desenvolvimento e expansão da oferta de cursos EAD, principalmente cursos superiores.

Saraiva (1995) destaca o conjunto de funções intercomplementares que compõem um sistema de EAD, que são: a administração ou gerência, planejamento, produção, utilização, acompanhamento, controle e avaliação. $\mathrm{Na}$ função utilização, o autor destaca a importância do planejamento, recepção, orientação e controle da aprendizagem, utilização pedagógica, supervisão, treinamento de recursos humanos, equipamentos e material de apoio, apoio logístico, acompanhamento e avaliação, e administração. 


\subsection{TECNOLOGIA NA PRÁTICA}

Várias são as definições e visões acerca do escopo e do papel da tecnologia nas organizações (Orlikowski, 1992; 2000; 2009). Segundo a autora (Orlikowski, 1992), a tecnologia não só é criada e alterada pela ação humana, mas também usada por seres humanos para realizar alguma ação. É a ação contínua do ser humano agindo habitualmente que objetiva e institucionaliza a tecnologia (Orlikowski, 1992).

Inspirada na teoria da estruturação de Giddens (1984), que reconhece que as ações humanas estão habilitadas e condicionadas pelas estruturas, ainda que elas sejam resultado de ações anteriores, Orlikowski (1992) propõe que a interação do homem com a tecnologia constitui a propriedade estrutural da organização. Propriedades estruturais, na definição de Giddens (1984), consistem nas regras e recursos que os agentes humanos utilizam na sua interação cotidiana. Essas regras e recursos medeiam a ação humana, enquanto, ao mesmo tempo, são reafirmadas por meio do uso de atores humanos.

A interação entre tecnologia e organização é uma função dos diferentes atores e contextos sócio-históricos, implicados no seu desenvolvimento e uso. Tecnologia, portanto, é fisicamente construída por atores que trabalham em determinado contexto social e é socialmente construída por atores por meio de diferentes significados e características que atribuem a ela. O modelo desenvolvido por Orlikowski é ilustrado a seguir, pela Figura 1.

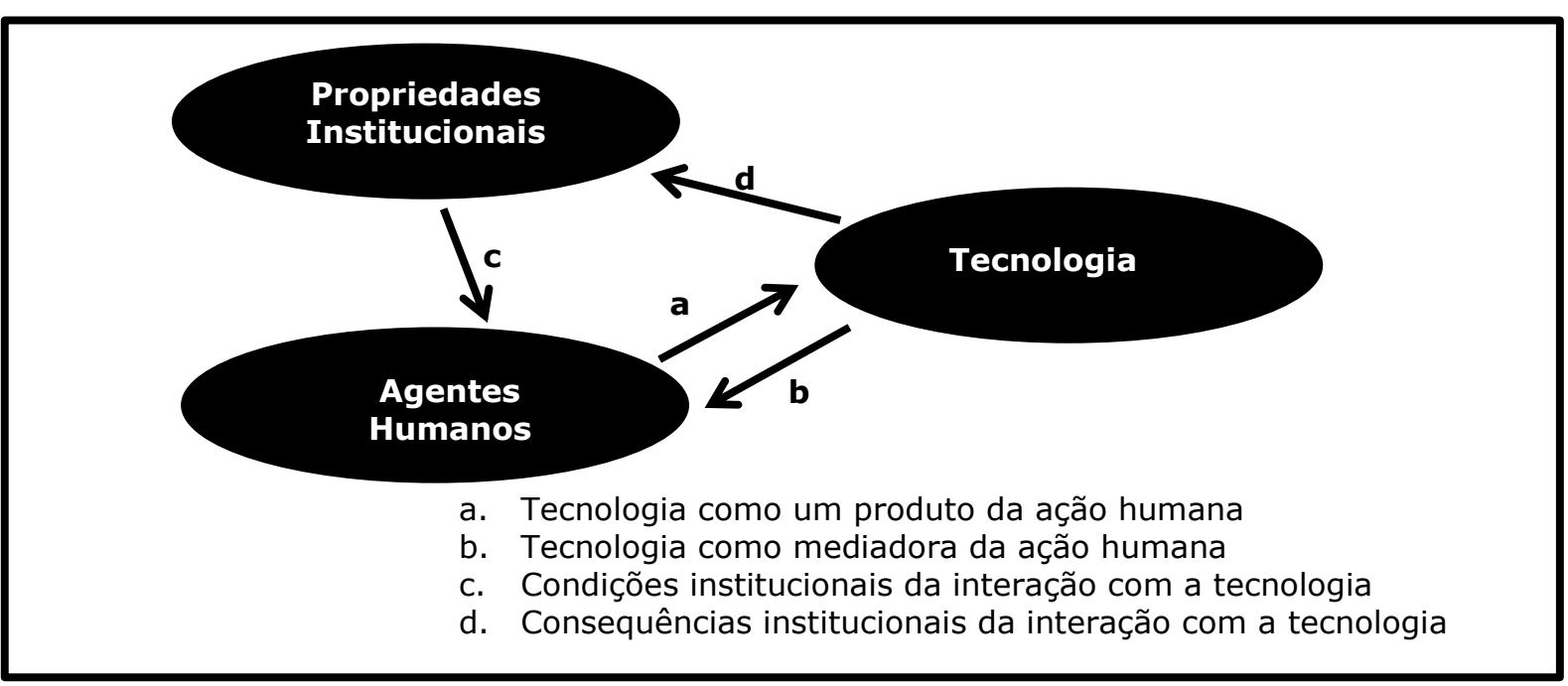

Figura 1: Modelo estruturacionista de tecnologia de Orlikowski (1992)

Fonte: Orlikowski (1992, p. 410) 
A dualidade da tecnologia permite ver a tecnologia como adotada pela agência humana e como institucionalizada na estrutura. Diante disso, existe a flexibilidade na forma como as pessoas projetam, interpretam e usam a tecnologia, considerando os componentes materiais que compõem o artefato, o contexto institucional em que uma tecnologia é desenvolvida e utilizada e o poder, o conhecimento e o interesse dos agentes humanos (desenvolvedores, usuários e gestores) (Orlikowski, 1992).

Conforme destaca Orlikowski (2000), nessa perspectiva da prática, os homens constituem as estruturas por meio do uso recorrente da tecnologia (Figura 2). Regras e recursos só existem nas e a partir das atividades dos agentes humanos. O uso da tecnologia torna-se estruturado pela agência humana, envolvendo uma composição de: experiência, conhecimento, significados, hábitos, relações de poder, normas e artefatos tecnológicos.

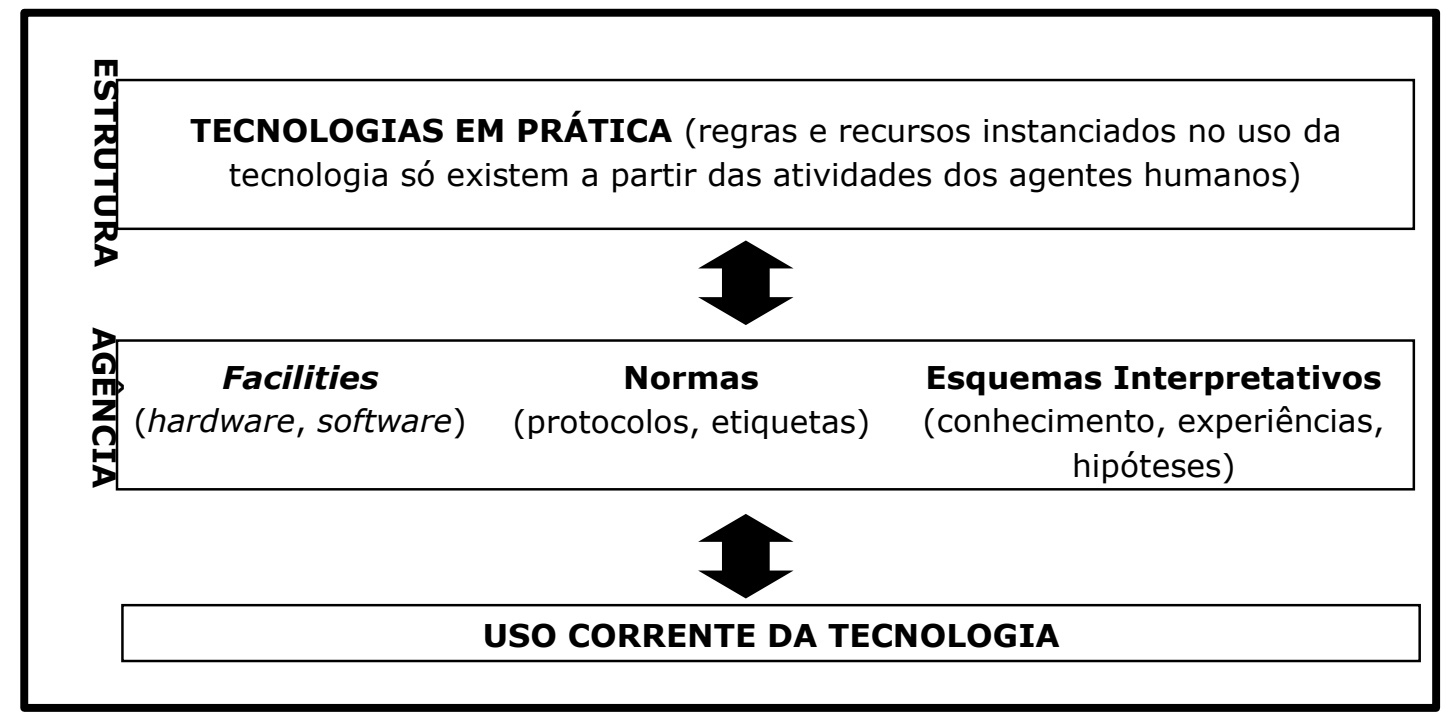

\section{Figura 2: Uso da tecnologia e constituição de estruturas}

Fonte: Orlikowski (2000)

A partir dessa perspectiva orientada pela prática, Orlikowski (2000) aponta que há uma maleabilidade do uso da tecnologia, que varia conforme a própria natureza do artefato. Os artefatos conceituais, como técnicas e metodologias expressas pela linguagem, situam-se no mais alto nível na hierarquia de intervenções possíveis. Num segundo nível de maleabilidade do uso, encontram-se os artefatos baseados em software. 
Essa perspectiva interativa e dinâmica da tecnologia é bastante adequada para as atividades de serviço, o qual, por definição, é um processo de realização de trabalho que envolve a ação combinada de trabalho humano e trabalho mecânico, realizado por máquinas e equipamentos (Meirelles, 2006).

Em função disso, a definição adotada de tecnologia neste artigo é: a aplicação de conhecimentos específicos sistematizados, ao processo de desenvolvimento de bens e serviços, envolvendo dinâmica e interativamente, pessoas, habilidades, artefatos e organizações, para alcançar fins determinados.

\subsection{COMPETÊNCIA TECNOLÓGICA}

De acordo com os autores ligados à visão baseada em recursos (RBV), competências referem-se a habilidades e conhecimentos que os gestores desenvolvem individual e coletivamente para melhorar, recombinar e mudar os serviços que os seus recursos oferecem (Penrose, 2006).

O conceito inicial de competência estava relacionado com a busca de uma abordagem mais efetiva para o processo de escolha de pessoas em organizações. Em seguida, ele foi ampliado para dar suporte a processos de avaliação de pessoas e para orientar ações de desenvolvimento profissional. 0 conceito de competência inclui também a caracterização de demandas para certos cargos ou para fixar ações ou comportamentos efetivos esperados. $\mathrm{O}$ conceito evoluiu e hoje inclui a ideia de agregação de valor e de entrega em determinado contexto (Fischer, Dutra, Ruas \& Nakata, 2006).

De acordo com Ruas (2005), a noção de competência envolve conhecimento, habilidades e atitudes, gerando a capacidade de entrega com certo desempenho. O autor argumenta que a noção de competência aproximase mais da capacidade de combinar e mobilizar adequadamente recursos já desenvolvidos do que de um estoque de conhecimentos e habilidades. Essa noção está relacionada com eventos em que novos problemas colocados pelo ambiente mobilizam a atividade de inovação (Zarifian, 2008). Trata-se do conceito de competência como ação (Sandberg, 2000; Le Boterf, 2003).

De acordo com Sandberg (2000), o conceito de competência requer uma visão do desempenho humano na realização do trabalho (human 
competence at work). Nesse sentido, a identificação das competências requer uma visão interpretativa, baseada no contexto e na experiência de cada indivíduo.

No nível específico da firma, os estudos de competência tecnológica envolvem atributos técnicos ligados ao desenvolvimento de produtos e processos (Danneels, 2002; Oakey, 2003), como atributos comportamentais, relacionados às habilidades de análise e uso da tecnologia (Sandberg, 2000; Ko \& Lu, 2010), e atributos de gestão, ligados à estratégia e ao mercado (Afuah, 2002). São estudos geralmente aplicados à indústria, em decorrência, os indicadores utilizados nem sempre se adéquam às atividades de serviço, como é o caso de patentes e gastos de P\&D.

De acordo com Fransman (1984), as capacidades tecnológicas envolvem habilidades, conhecimento e experiência necessários para: i) busca e seleção de alternativas tecnológicas; ii) domínio de tecnologias selecionadas e uso eficiente destas na transformação de insumos em produtos; iii) adaptação de tecnologias para condições específicas de produção e demandas locais; iv) obtenção de melhoramentos tecnológicos a partir de inovações incrementais; v) instituição de atividades de pesquisa e desenvolvimento; vi) desenvolvimento de pesquisa básica.

De acordo com Lall (1992), a capacidade tecnológica envolve não só a habilidade técnica, mas também a habilidade de investimento e de coordenação. Nesse sentido, envolve três tipos de capacidades: i) investimento; ii) produção; iii) coordenação (linkage).

As capacidades de investimento estão relacionadas às habilidades necessárias para identificar, preparar e obter tecnologia para design, construção, equipamentos, equipe, dentre outros. São habilidades fundamentais na definição da eficiência tecnológica. A capacidade de produção envolve desde habilidades básicas como controle de qualidade, operação e manutenção até pesquisa, design e inovação. As habilidades de produção determinam não só como as tecnologias são operadas e melhoradas, mas também os esforços internos à firma para absorver novas tecnologias ou imitá-las. As capacidades relacionais incluem as habilidades necessárias a transmissão e recebimento da informação, componentes ou matéria-prima, de fornecedores, consultores, firmas de serviços e instituições tecnológicas. (Lall, 1992). 
Essas três capacidades variam em grau de complexidade, sendo as capacidades básicas acumuladas a partir de rotinas de produção e as intermediárias ou avançadas a partir de esforços explícitos de capacitação, como a instituição de atividades de pesquisa e desenvolvimento.

Esta pesquisa está orientada segundo o pressuposto fundamental de que o desenvolvimento da competência tecnológica em serviços ocorre a partir do uso da tecnologia, em coordenação com recursos humanos, e dos seus impactos nas práticas organizacionais. A interação entre tecnologia e organização é função dos diferentes atores e do contexto sócio-histórico, o que implica variações tanto do ponto de vista do desenvolvimento e uso da tecnologia quanto da formação das competências tecnológicas.

O modelo proposto (Figura 3) considera que um processo cíclico de desenvolvimento da competência tecnológica da organização é constituído por três pilares: tecnologias utilizadas, agentes humanos (desenvolvedores, gestores e usuários finais) e práticas envolvidas no uso dessa tecnologia, a qual é projetada e desenvolvida pelos gestores e desenvolvedores e disponibilizadas para utilização dos gestores e ou usuários finais (1). A utilização da nova tecnologia leva ao desenvolvimento de novas práticas (2). As práticas vivenciadas pelo grupo (desenvolvedores, gestores e usuários) serão integradas ao conjunto de competências do grupo (3) e também influenciarão o desenvolvimento da própria tecnologia, que sofre alterações recorrentes em relação ao projeto original (4). Essa interação recorrente entre a tecnologia, os agentes humanos e a prática influencia o desenvolvimento da competência tecnológica da organização, que é, portanto, o resultado desse processo cíclico. 


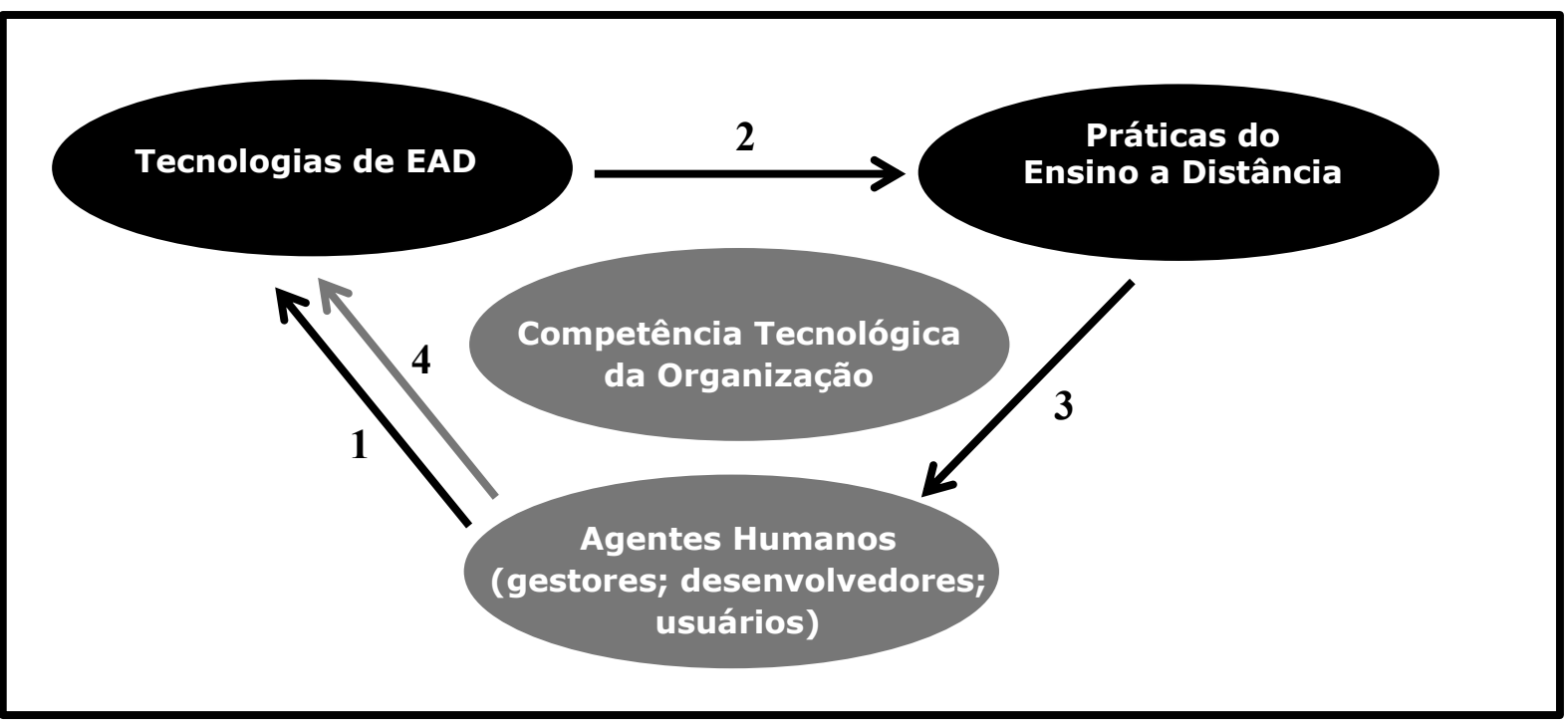

Figura 3: Modelo de desenvolvimento de competência tecnológica

Fonte: elaborada pelos autores

Esses pilares de desenvolvimento da competência tecnológica constituem as metacategorias analisadas nesta pesquisa.

\section{METODOLOGIA}

Esta pesquisa é um estudo exploratório uma vez que consiste na descrição e na compreensão de determinado fenômeno (Blaikie, 2003), neste caso, as competências tecnológicas em serviços.

Foi realizada uma pesquisa qualitativa interpretativa básica. Buscou-se atender aos objetivos específicos de identificar as tecnologias utilizadas no segmento de EAD bem como as especificidades no uso da tecnologia.

Foram coletados dados primários por meio de entrevistas realizadas com desenvolvedores e usuários (gestores e usuários finais) de tecnologias de EAD. Entrevistaram-se seis agentes no segmento de EAD, sendo três no segmento de e-learning corporativo, da empresa Kaptiva (sócio-diretor, gerente e gestor usuário), e três no segmento de educação a distância no ensino superior. No segmento de ensino superior, foram entrevistados um especialista em tecnologias educacionais, ligado à Universidade Estadual de Campinas (Unicamp), e dois usuários (gestor e coordenador de polo), ligados à Universidade de Franca (Unifran). 
Segundo Patton (2002), não há regras para o tamanho da amostra em pesquisas qualitativas, o recomendado é que exista um número mínimo de participantes que responda de maneira razoável ao problema de pesquisa. Considerando o caráter dual da tecnologia nas organizações, em que produção e uso se inter-relacionam de maneira dinâmica no tempo e no espaço, foram realizadas entrevistas com três perfis de entrevistados: desenvolvedores, usuários gestores e usuários finais (equipes das empresas).

O roteiro de perguntas aplicado foi semiestruturado, com algumas questões relativas às características da tecnologia adotada e às competências tecnológicas desenvolvidas. Em linhas gerais, os seguintes aspectos foram contemplados no roteiro das entrevistas: i) perfil dos agentes (desenvolvedores e usuários): conhecimentos, habilidades e atitudes; ii) tecnologia: definição; tecnologias utilizadas, tecnologias fundamentais e de fronteira, estrutura do sistema de informação, adoção (motivos do uso) e forma de desenvolvimento (interno ou terceirizado); iii) tecnologia e usuários: processos de desenvolvimento, implantação e atualização tecnológica; iv) tecnologia e resultados: práticas organizacionais, competências individuais, investimentos adicionais, vantagem competitiva, desempenho econômico e operacional

\section{APRESENTAÇÃO E ANÁLISE DE DADOS}

Nos procedimentos de análise de dados, seguiu-se o modelo de análise textual proposto por Flores (1994), que se baseia num sistema de metacategorias e categorias. A estruturação das categorias em metacategorias leva à construção do sistema de categorias, conforme definido pelo autor. As quatro metacategorias desta pesquisa são: tecnologia, processos, mudanças e impactos econômicos.

\subsection{TECNOLOGIA}

Na visão do desenvolvedor de e-learning corporativo, tecnologia em EAD é ampla, podendo envolver não apenas OAs, mas também incluir a plataforma, em que esses objetos e conteúdos vão ser hospedados: "A gente 
tem a tecnologia nos objetos e tem a plataforma. Então são duas coisas que são intensas. No objeto, a forma de fechamento desse núcleo duro pode ser muita coisa. Eu posso pegar um PDF, colocar no site e falar que isso é elearning, porque de fato isso é. Mas eu posso ter uma página em HTML ou eu posso ter animações em Flash ou jogos simuladores ou um vídeo. Tudo isso é e-learning [...] E aí depois, tem a tecnologia da plataforma. Onde você vai hospedar esses conteúdos..." (desenvolvedor - sócio diretor).

No segmento de ensino superior, a tecnologia, na visão do Gestor de Polos Universitários, está relacionada à função que ela cumpre de "levar o ensino de qualidade a centros distantes..., um papel importante hoje, que é levar o ensino de qualidade para muitos brasileiros" (gestor de polos universitários).

Na visão do coordenador de polos universitários, a tecnologia de EAD está ligada às ferramentas, os meios, que possibilitam levar a informação com mais rapidez para as pessoas: "... um meio de transporte, é o caminho de você levar a informação às pessoas" (coordenador de polos universitários)

Interessante observar na visão do usuário especialista em Tecnologias Educacionais, uma perspectiva que, além da distância, foca no processo de aprendizado, denominado por ele de "aprendizagem por investigação". Para ele, na caracterização da tecnologia de EAD, não importa o dispositivo utilizado (celular, tablet ou computador), mas "como está sendo feita a mediação entre a informação e o que o aluno está fazendo".

Nesse sentido, não importa onde o aluno está, o relevante é "o aluno ativo, buscando informação e usando essa informação para resolução de problemas". O papel do professor nesse processo é de "certificação", proporcionando o sistema adequado de modo que o aluno cumpra o solicitado.

"O foco não está na tecnologia. Do jeito que ele está fazendo aqui, não interessa... Ele pode estar na biblioteca lendo um livro. [...] O que a gente tem que pensar ... é: como eu monto esse esquema, de modo que esse sujeito possa ter acesso à informação, para ele não sair catando, procurando?" (usuário especialista em Tecnologias Educacionais). 
Na visão desse entrevistado, o foco está no que é feito por professores e alunos, numa visão congruente com a proposta estruturacionista de abordagem da tecnologia proposta por Orlikowski (2000), em que o uso e a estruturação da tecnologia inicia-se com a ação humana, fazendo emergir estruturas por meio da interação recorrente entre pessoas, tecnologias e ação social. Nesse sentido, ele cita o exemplo de uma ferramenta de ensino, denominada ToolDo, voltada para o uso de base de dados.

Em relação às plataformas utilizadas, no segmento de e-learning, o Moodle é a ferramenta mais comum. Embora aponte restrições de funcionalidades, o entrevistado destaca que a plataforma é de fácil uso, pois não é necessário ser um programador para utilizá-la. Além da funcionalidade, o entrevistado pontua seu baixo custo. "[...] o Moodle é friendly. Se você usar ele no básico, não precisa ser um programador... o Moodle é uma opção muito mais barata" (desenvolvedor - sócio diretor).

As plataformas usadas no segmento de ensino universitário são, conforme afirma o gestor de polos universitários, uma composição de portal (plataforma virtual) com material impresso e os próprios polos, onde o aluno interage presencialmente. As plataformas virtuais, utilizadas no polo do interior de São Paulo, incluem o Tecfad e o Blackboard.

Na Unifran, segundo o gestor coordenador de polos, todo o sistema de EAD é criado, produzido e gerenciado internamente. A universidade tem portal próprio e não utiliza produtos de prateleira, desenvolvendo todo o conteúdo internamente (criação/gravação de aulas, materiais de apoio, tutoria, etc.). Tanto o desenvolvimento quanto a atualização são feitos a partir das necessidades da instituição, e apenas algumas atividades, como divulgação e atendimento aos alunos, são feitas pelos polos.

$\mathrm{Na}$ Unicamp, segundo o usuário especialista em Tecnologias Educacionais, a plataforma utilizada é toda TelEduc, desenvolvida pela universidade em 1998, mas o Moodle também tem sido disponibilizado para escolha de alunos e professores.

O Moodle, segundo o entrevistado, apesar de bastante popular, é "complicado, muito confuso" exigindo adaptações. Na sua avaliação como usuário, o bom é evitar alterações, para isso a plataforma deve ser mais 
padronizada. Nesse sentido, ele cita também o Sacai, plataforma parecida com o TelEduc.

Além das plataformas virtuais, o entrevistado destaca o uso de ferramentas para gerar material, como o ToolDo, que, segundo ele, "não tem nada a ver com EAD", sendo utilizada pelos professores para desenvolver material didático para uso em sala de aula. É uma ferramenta livre, com manual de instalação e uma base de dados.

Na avaliação do desenvolvedor de e-learning corporativo, a estrutura do sistema de informação (hardware, software e pessoas) varia conforme o porte e a demanda da empresa. A infraestrutura inclui equipe de produção e de gestão.

No caso do segmento de ensino superior, a Unifran possui sete estúdios e um grupo de seis a oito pessoas de atendimento. Em termos de sistema de informação, inclui, além do servidor próprio, um software para transmitir as aulas ao vivo. No polo do interior de São Paulo, o pessoal envolvido na gestão do sistema é composto por quatro pessoas, incluindo a coordenadora. Na sua avaliação, a estrutura é muito simples, com "um software de Internet, um Flash Player, um Adobe", é possível "fazer, tanto aulas presenciais, como virtuais". Além do pessoal, a entrevistada citou a infraestrutura de telecomunicação, com duas bandas largas.

Quanto à Unicamp, o usuário especialista em tecnologias educacionais destaca a estrutura do Grupo Gestor de Tecnologias Educacionais (GGTE), com seis pessoas exercendo funções diversas, "duas para revisão e material midiático, se é proprietário ou não, e quatro pessoas que fazem a geração de simulação, animação, vídeo". Todavia professores também se envolvem na geração de material didático, além dos alunos de mestrado e doutorado, que são tutores dos cursos.

Em relação à infraestrutura de EAD, o entrevistado destaca que "está tudo centralizado no Centro de Computação". O acesso é todo via Internet e o uso da tecnologia é livre, inclusive com estímulo ao uso de bases de dados. 0 entrevistado destaca também a necessidade de ampliação da capacidade de armazenamento de dados, como sistemas nas nuvens e de blades (sistema de memória de computadores com vários processadores atuando simultaneamente). 
No segmento de ensino universitário, na visão do gestor de polos Universitários, "a tecnologia está muito mais rápida". O uso do tablet e do celular proporcionam novas possibilidades: "De repente você clica lá e tem a sua aula disponível. E isso vai melhorar muito".

Por outro lado, segundo o coordenador de polos Universitários, ele não conhece "nenhuma tecnologia inovadora, nada tão diferente do que se utiliza já hoje", mas acredita que novas devam surgir.

Além do uso de dispositivos e veículos de comunicação voltados para mobilidade, como o Skype, o usuário especialista em Tecnologias Educacionais, numa perspectiva ampla de uso de tecnologias educacionais, destaca o uso de técnicas de aprendizagem baseada na solução de problemas (sigla em inglês PBL - problem based learning), como o Flipped Classroom, utilizado no Massachusetts Institute of Technology (MIT). "Assim, em matéria de tecnologias educacionais, eu não vou falar de educação à distância. É o Flipped Classroom. Esse é o gol para a gente poder chegar lá. É, o MIT já faz isso faz tempo."

\subsection{TECNOLOGIAS E USUÁRIOS}

O processo de desenvolvimento das tecnologias de EAD, notadamente 0

e-learning corporativo, deu-se de forma totalmente interna à empresa. Conforme relata o entrevistado desenvolvedor - sócio diretor, o treinamento pela Internet era uma novidade à época em que ele decidiu entrar no segmento.

No ensino universitário, a Unicamp foi pioneira no desenvolvimento de uma plataforma própria (TelEduc), fruto de uma iniciativa do Núcleo Interdisciplinar Aplicado à Educação, que trabalhava com as tecnologias da informação nas escolas.

Na Unifran, a EAD iniciou-se com a compra de um software para transmissão de aulas, que posteriormente sofreu uma série de adaptações. Segundo o gestor de polos, "a implantação... não foi nada fácil". Toda a atualização, segundo ele, é feita dentro da universidade. A principal motivação 
para a atualização é uma mescla de competição, de "olhar os concorrentes", até treinamentos e participações em feiras, inclusive internacionais.

A implantação do EAD na Unicamp, segundo o usuário especialista em Tecnologias Educacionais, sofreu vários entraves, principalmente por parte dos alunos, inclusive com greves. Em função disso, nota-se que a instituição adotou uma política mais aberta, no sentido de não impor as novas tecnologias, bem como adotar uma orientação mais ampla de tecnologias educacionais, não necessariamente voltadas para o EAD. Isso explica, por exemplo, por que os professores hoje adotam o Moodle, e não o TelEduc, plataforma própria da Unicamp.

Com essa nova orientação para o uso das tecnologias educacionais mais interativas e livres, segundo o entrevistado, os professores envolveramse mais, tornando-se mais ativos no processo de desenvolvimento. Como resultado, a participação dos alunos tem sido mais intensa e criativa, ao mesmo tempo que o professor tem mais flexibilidade de trabalho.

Em função de uma política mais "solta" de uso da tecnologia, nota-se que não há cobrança dos alunos. Nesse sentido, a instituição está fazendo um levantamento sobre como essas tecnologias são utilizadas, e mesmo o treinamento não é sistematizado.

Nos polos de EAD da Unifran, segundo o gestor dos polos universitários, foram realizados "muitos investimentos em capacitação, treinamento e postura". Essa declaração confirma-se na fala da coordenadora de um dos polos da universidade, quando afirma que, apesar de no início não existir treinamento interno, a instituição evoluiu para reuniões semanais de feedback para discussão de conteúdo e de infraestrutura tecnológica.

Já para o desenvolvedor de e-learning corporativo, não há treinamento interno sistemático, apenas, de vez em quando, alguns workshops. Além desses, o entrevistado busca treinamentos oferecidos por empresas especializadas. Além disso, a busca por profissionais tem se dado a partir de egressos de cursos em instituições de ensino: "Treinamento interno, nosso, não temos. De vez em quando, a gente faz alguns workshops internos". (desenvolvedor - sócio diretor) 
A competência dos usuários, no segmento específico de e-learning corporativo, reflete, segundo o desenvolvedor, a própria origem do segmento. É uma combinação de profissionais com competência em publicidade, programação de sites, pedagogia e recursos humanos. O entrevistado destaca o tutor como profissional que deve possuir competências relacionadas ao domínio das tecnologias utilizadas (ligadas à comunicação em mídias sociais) e, ao mesmo tempo, ser um facilitador.

Interessante observar que, diferentemente do EAD acadêmico, no elearning corporativo, de acordo com o desenvolvedor de e-learning entrevistado, o professor é ausente: "No corporativo é muito raro você ter a figura do professor. A maioria dos cursos são autoinstrucionais. Eles não querem essa dinâmica de turma. Então, você vai lá, faz um curso que a pessoa vai clicando, interagindo e no final ela faz uma avaliação e ok. É muito rara a figura do professor" (desenvolvedor - sócio diretor)

Já, diferentemente da visão do usuário especialista em Tecnologias Educacionais, na visão do desenvolvedor de e-learning, o professor no EAD acadêmico, embora atue significativamente, poderia ser "descartável", já que, na sua opinião, "o professor não é importante", pois o conteúdo está disponível e nem sempre ele sabe escrever um livro didático.

$\mathrm{Na}$ visão do gestor de polos universitários, o EAD exige desenvolvimento de novos recursos e habilidades, como falar para uma câmera e ser motivador.

Interessante observar que o aluno do e-learning corporativo é, na avaliação do desenvolvedor, bastante ativo, já que é uma "oportunidade de desenvolvimento", mas essa postura favorável ou não ao EAD depende do departamento de Recursos Humanos $(\mathrm{RH})$ do ambiente corporativo. Como critérios principais, o entrevistado cita o baixo custo, a atratividade ("tem que ser muito vistoso").

Além disso, às vezes a postura do RH é muito "impositiva", o aluno "tem que clicar todas as telas para passar para a próxima", dificultando a navegabilidade.

Em contrapartida, o aluno acadêmico surpreende-se com o grau de exigência do ensino a distância: "... é muito puxado fazer um curso à distância. 
É muito mais puxado do que fazer um curso presencial" (desenvolvedor sócio-diretor)

Conforme destaca o coordenador de polos universitários, o ensino a distância exige seriedade e vontade de aprender, pois é preciso ser autodidata.

\subsection{TECNOLOGIAS E RESULTADOS}

A implantação do e-learning corporativo, de acordo com a avaliação do desenvolvedor de e-learning, tem como impacto a redução de custo, seja a redução de custos de "deslocamento, hotel, conciliar agenda, tirar o profissional do trabalho", ou mesmo a de replicação do treinamento, notadamente quando há muitos alunos.

Por outro lado, no EAD acadêmico, embora o objetivo seja redução de custos, é improdutiva uma turma entre 20 e 40 alunos, pois é difícil promover a dinâmica em salas de aula acima desse patamar.

$\mathrm{Na}$ avaliação do gestor de polos universitários, o EAD proporciona maior rentabilidade para qualquer instituição, pois "é uma estrutura mais enxuta, viável, com possibilidade de uma melhor qualidade". Essa é uma tendência para qualquer instituição que busque esses resultados, "tanto é que grandes instituições internacionais estão adquirindo empresas, universidades no Brasil". O desempenho econômico efetivo, entretanto, conforme afirma o entrevistado, ainda não ocorreu.

$\mathrm{Na}$ visão do coordenador de polos universitários, o EAD é "extremamente lucrativo", pois é possível utilizar uma aula gravada por "no mínimo cinco, seis anos". Ao mesmo tempo em que é lucrativa, a atividade exige investimentos constantes. O desenvolvedor de e-learning destaca a necessidade de adaptação ao tablet, pois é necessário outra linguagem e redimensionamento: "Então o que está na tela do computador, se você reduzir e colocar aqui, não cabe. Aquele click que você tinha que dar naquela tela é impossível..." (desenvolvedor - sócio diretor)

No caso do EAD acadêmico, os entrevistados destacam como muito altos o crescimento e a necessidade de investimento. De acordo com o coordenador de polos universitário, à medida que a qualidade dos programas e ferramentas melhora, tornam-se necessários investimentos em novos 
equipamentos e Internet. Além disso, o gestor de polos universitários aponta a necessidade de "uma biblioteca básica e fundamental em cada polo".

$\mathrm{Na}$ opinião do desenvolvedor de e-learning, apesar do incentivo de redução de custo, o impacto efetivo, notadamente no corporativo, só vem a partir da criação de uma cultura de e-learning, desenvolvida a partir do uso. Mas, segundo o entrevistado, é difícil desenvolver essa cultura, pois o elearning ainda é visto como fuga do trabalho. Apesar disso o e-learning corporativo, ainda segundo o mesmo entrevistado, é uma tendência, uma modalidade que complementa o presencial, e não é possível as empresas serem refratárias, já que em alguns casos é uma necessidade, como nas redes de franquias.

No ambiente corporativo, por exemplo, grandes redes atacadistas, como o Armazéns Martins, têm utilizado o treinamento EAD para obter vantagem competitiva. Por meio da Universidade Martins, a empresa tem formado pequenos varejistas para criar vínculo entre fornecedor e varejo, garantindo exclusividade de vendas.

A vantagem competitiva para o desenvolvedor de e-learning, notadamente para o pequeno desenvolvedor, reside essencialmente na diferenciação (atenção e acompanhamento do cliente), pois a concorrência com grandes empresas tem sido prejudicial.

Nesse sentido, notadamente para as universidades, segundo a visão do desenvolvedor de e-learning, a vantagem competitiva do EAD é visível, uma vez que é possível ofertar cursos com alta qualidade.

A qualidade também é destacada pelos entrevistados do segmento de ensino universitário, uma vez que, segundo o gestor de polos universitários, o crescimento da universidade precisa se dar "não só com o número de alunos, mas mantendo qualidade de ensino".

O EAD, segundo o gestor de polos universitários, "não só atende a qualidade, como muitas vezes até supera. Os resultados podem ser vistos nas provas do Enade, da educação a distância, que refletiu no presencial".

Além dos impactos em termos econômicos e de qualidade, há mudanças nas práticas organizacionais e nas competências. No segmento de ensino universitário, as principais mudanças ocorrem nas práticas de ensino. 
Na visão do gestor de polos universitários, a principal é a velocidade. Há "uma necessidade de resposta mais veloz, seja na tramitação dos documentos ou em uma resposta da tutoria". Outro impacto é, para o mesmo entrevistado, a melhoria na qualidade do ensino, pois "é possível gerenciar o aluno... fazer com que ele absorva muito mais informações".

No caso do e-learning corporativo, a despeito de já existirem sistemas de avaliação/feedback de aprendizado, de acordo com o desenvolvedor de elearning, esses impactos não são medidos.

De acordo com o gestor de polos universitários, as mudanças nas competências do professor a partir das práticas de EAD são inúmeras, pois "falar para uma câmera e você conseguir ser motivador, conseguir transmitir, requer uma série de habilidades".

O EAD promove uma ampliação do leque de melhorias disponíveis ao professor, pois, conforme destaca o coordenador de polos universitários, ele "pode fazer diversos cursos para melhorias... criar suas próprias animações", além de ter acesso a "informações e dados".

Em relação às mudanças nas competências dos alunos, o coordenador de polos universitários destaca o próprio "contato com a tecnologia". Essa exigência fez com que o EAD hoje seja visto como sério, pois, "todo mundo achava que era compra de diplomas e esquecia a parte que o aluno precisa fazer, aprender, entrar na plataforma, estudar e ser muito autodidata".

As mudanças exigidas nas competências do professor envolvem também mudança de atitudes. De um lado, conforme avalia o usuário especialista em Tecnologias Educacionais, o professor se incomoda com as novas tecnologias educacionais, por exemplo, com o aluno que utiliza celular. Mas, para o entrevistado, o importante é não confrontar o aluno, mas, sim, criar condições para ele utilizar as novas ferramentas.

Por outro lado, o professor muda sua atitude ao perceber que o uso das tecnologias de EAD proporciona maior organização, menos papel, e os alunos também gostam dessa organização, pois dá maior previsibilidade.

Já, na visão do usuário especialista em Tecnologias Educacionais, outra mudança proporcionada por essas tecnologias é a otimização do tempo em sala de aula. 
Como resultado, os mecanismos de avaliação também mudam, a presença em sala, por exemplo, não é mais relevante e o importante é o aluno resolver o problema proposto pelo professor e entregar os relatórios nas datas solicitadas. O papel do professor é ser certificador e consultor, ajudando o aluno a resolver problemas.

A mudança na dinâmica da aula presencial, com menos tempo em sala, gera mais liberdade e flexibilidade, mas, por outro lado, exige do aluno responsabilidade com prazos e resultados, o que exige também senso crítico.

O resultado principal da utilização das tecnologias baseadas na solução de problemas é, segundo o usuário especialista em Tecnologias Educacionais, a redução do índice de reprovação. E, nesse processo de aprendizagem investigativa, até aumenta o nível de presença, pois o aluno passa a interessarse mais pelo ambiente de estudo.

\section{CONSIDERAÇÕES FINAIS}

O objetivo geral deste estudo foi identificar as competências tecnológicas em serviços, de acordo com as especificidades inerentes a essas atividades, tendo como pressuposto que desenvolvimento da competência tecnológica em serviços de EAD ocorre a partir do uso da tecnologia, em coordenação com recursos humanos; e os seus impactos nas práticas organizacionais.

Observou-se que as tecnologias utilizadas vão além das plataformas de ambientes virtuais, englobando sobretudo objetos de aprendizagem (vídeos, material impresso, etc.) que proporcionam a realização do ensino a distância.

O envolvimento dos usuários é intenso, seja na adaptação da plataforma, seja no desenvolvimento de conteúdo. Nesse sentido, nota-se maior apropriação da tecnologia.

Nota-se também que o uso de plataformas EAD é uma tendência ditada pela concorrência, mas a forma como as instituições utilizam essas plataformas varia. As duas instituições analisadas (uma pública e outra privada) apresentam diferentes dinâmicas quanto à articulação de conhecimento, 
habilidades, pessoas e artefatos que, em conjunto, definem as competências desenvolvidas.

$\mathrm{Na}$ instituição pública, a política de uso das plataformas e a dinâmica em aula é mais livre, o que sinaliza o desenvolvimento de novas técnicas de aprendizagem, pautadas pelo desenvolvimento do senso investigativo e crítico dos alunos. Em contrapartida, na instituição privada, a política de uso mais direcionada proporciona um maior gerenciamento do aluno.

Conforme o usuário especialista em tecnologias educacionais aponta, com o avanço da Internet e o uso crescente de dispositivos móveis, é preciso mudar as práticas de ensino, pautadas na aprendizagem investigativa. Para isso é preciso ir além da tecnologia e desenvolver novas técnicas de aprendizagem pautadas na solução de problemas.

Em conjunto, a articulação de conhecimento, habilidades, pessoas e artefatos definem competências tecnológicas distintas.

As principais fontes de capacitação dos usuários das tecnologias de EAD são o treinamento a distância e a prática no ambiente de trabalho, sendo às vezes aplicados treinamentos presenciais. O conhecimento básico de informática e das rotinas e procedimentos para utilização da plataforma virtual são os mais importantes para utilização das tecnologias de EAD, na avaliação dos respondentes.

Em relação às habilidades necessárias para utilização das tecnologias de EAD, os respondentes destacaram compartilhamento de conhecimento, análise e solução de problemas e execução ordenada de tarefas. Do ponto de vista das atitudes desejáveis para utilização das tecnologias de EAD, os respondentes apontaram como muito importante a aceitação do novo, a busca de novos conhecimentos, a colaboração com os colegas de trabalho e o interesse em aprender novas tecnologias.

Em função do tamanho restrito da amostra, há restrições de generalização. Espera-se que, com a ampliação do escopo, por meio de uma pesquisa quantitativa, se possa avançar na identificação dos fatores componentes da competência tecnológica em serviços. 


\section{REFERÊNCIAS}

Associação Brasileira de Educação a Distância - ABED. (n.d). Recuperado em 4 de setembro, 2012, de http://www2.abed.org.br/

Afuah, A. (2002). Mapping technological capabilities into product markets and competitive advantage: the case of cholesterol drugs. Strategic Management Journal, 23(2), 171-179.

Anderson, T., \& Dron, J. (2012). Três gerações de pedagogia de educação a distância. EAD em Foco, 2(1).

Assis, E. M. (2012). Satélites artificiais e a EAD. In F. M. Litto, \& M. Formiga, Educação a distância: o estado da arte. São Paulo: Pearson Education do Brasil.

Behar, P. A., Ribeiro, A. C. R., Schneider, D., Silva, K., Machado, L. R., \& Longhi, M. T. (2013). Educação a distância e competências: uma articulação necessária. In P. A. Behar (Org.), Competências em Educação a Distância (vol. 1, pp. 42-54). Porto Alegre: Penso.

Blaikie, N. (2003). Analyzing quantitative data: From description to explanation. London: Sage.

Clarenc, C. A., Castro, S. M., Carmen López, M. E. M., \& Tosco, N. B. (2013, December). Analizamos 19 plataformas de e-Learning: investigación colaborativa sobre LMS. Grupo GEIPITE, Congreso Virtual Mundial de eLearning. Recuperado de: http://www. congresoelearning.org.

Danneels, E. (2002). The dynamics of product innovation and firm competences. Strategic Management Journal, 23(12), 1095-1121.

Fernandes, R. R., Fernandes, A. P. L. M., Silva, A. C. M. da, Araújo, M. O., \& Cavalcante, M. C. T. (2010). Moodle: uma ferramenta on-line para potencializar um ambiente de apoio à aprendizagem no curso Java Fundamentos (JSE). Anais do Simpósio de Excelência em Gestão e Tecnologia, 7, Resende, RJ, Brasil.

Fischer, A. L., Dutra, J. S., Ruas, R. L., \& Nakata, L. E. (2006). Absorção do conceito de competência em gestão de pessoas: a percepção dos profissionais e as orientações adotadas pelas empresas. Anais do Encontro da Associação Nacional de Pós-Graduação e Pesquisa em Administração, 30, Salvador, BA, Brasil.

Flores, J. G. (1994). Análisis de datos cualitativos: aplicaciones a la investigación educativa. Barcelona: Promociones y Publicaciones Universitarias.

Fransman, M. (1984). Technological capability in the Third World: an overview and introduction to some of the issues raised in this book. In M. Fransman, \& K. King (Eds), Technological capability in the Third World (pp. 3-30). London: Macmillan. 
Giddens, A. (1984). A constituição da sociedade. São Paulo: Martins Fontes.

Ko, Hsien-Tang, \& Lu, Hsi-Peng. (2010). Measuring innovation competencies for integrated services in the communications industry. Journal of Service Management, 21(2), 162-190.

Lall, S. (1992). Technological capabilities and industrialization. World development, 20(2), 165-186.

Le Boterf, G. (2003). Desenvolvendo a competência dos profissionais. Porto Alegre: Artmed.

Machado, L. R., Longhi, M. T., \& Behar, P. A. (2013). Domínio tecnológico: saberes e fazeres. In P. A. Behar (Org.), Competências em Educação a Distância (vol. 1, pp. 56-80). Porto Alegre: Penso.

Maia, M. (2012). Ferramentas da Web 2.0 associadas aos LMS no ensino presencial. In F. M. Litto, \& M. Formiga, Educação a Distância: o estado da arte. São Paulo: Pearson Education do Brasil.

McKelvey, B. (1982). Organizational systematics - taxonomy, evolution, classification. Berkeley, CA: University of California Press.

Meirelles, D. S. (2006). The concept of service. Revista de Economia Política, 26(1), 119-136.

Nelson, R. R., \& Winter, S. G. (1982). An evolutionary theory of economic change. Cambridge, MA: Harvard University Press.

Oakey, R. P. (2003). Technical entrepreneurship in high technology small firms: some observations on the implications for management. Technovation, 23(8), 679-688.

Orlikowski, W. J. (1992). The duality of technology: rethinking the concept of technology in organizations. Organization Science, 3(3), 398-427.

Orlikowski, W. J. (2000). Using technology and constituting structures: A practice lens for studying technology in organizations. Organization Science, 11(4), 404-428.

Orlikowski, W. J. (2009). The sociomateriality of organisational life: considering technology in management research. Cambridge Journal of Economics, 34, 125-141.

Patton, M. Q. (2002). Qualitative research \& evaluation methods. London: Sage.

Penrose, E. T. (2006). A teoria do crescimento da firma. Campinas: Editora da Unicamp.

Peters, O. (1973). A estrutura didática da educação a distância. São Paulo: Olho d'Água. 
Ruas, R. (2005). Gestão por competências: uma contribuição à estratégia das organizações. In R. Ruas, C. S. Antonello, \& L. H. Boff, Os novos horizontes de gestão: aprendizagem organizacional e competências (pp. 34-55). Porto Alegre: Bookman.

Rumble, G. (2000). A tecnologia da educação a distância em cenários do terceiro mundo. In O. Preti (Org.), Educação a distância: construindo significados (pp. 43-63). Cuiabá: NEAD/IE-UFMT.

Sandberg, J. (2000). Understanding human competence at work: an interpretative approach. Academy of Management Journal, 43(1), 9-25.

Saraiva, T. (1995). Avaliação da educação a distância: sucessos, dificuldades e exemplos. Boletim Técnico do Senac, 21(3).

Santos, J. R. (2012). A Moodle nas práticas pedagógicas de uma escola básica: realidade ou ficção na inserção das TIC em sala de aula. Educação, Formação \& Tecnologias, 5(1), 72-83.Taylor, J. C. (2002, October). Automating e-Learning: the higher education revolution. Proceedings of the Annual Conference of the German Informatics Society, 32, Dortmund, Germany.

Teece, D. J., Rumelt, R., Dosi, G., \& Winter, S. (1994). Understanding corporate coherence: theory and evidence. Journal of Economic Behavior \& Organization, 23(1), 1-30.

Versuti, A. (2004). Avaliação formativa e qualidade em Ead. Anais do Congresso Internacional de Educação a Distância, 11, Salvador, BA, Brasil.

Zarifian, P. (2008). Objetivo competência: por uma nova lógica. São Paulo: Atlas. 